\title{
Report Writing in ESP Classes for Advanced Level Students
}

\author{
Troy B. Wiwczaroski \\ University of Debrecen, Centre of Agricultural Sciences, \\ Faculty of Agricultural Sciences, \\ Centre of Technical Languages Instruction, Debrecen
}

\section{SUMMARY}

The author discusses the importance of formal training in writing, and introduces, step-by-step, the requirements and conventions of writing necessary for all university students to master. In doing so, he points to gaps, both in curricula and in student knowledge, which first need to be addressed, in order to ensure institutions meet successful educational goals.

Solid report writing is the key to educating advanced students to hone their abilities in reading, writing and, if then presented orally, speaking.

Instructors might assume that reliance on a written assignment would alone provide students with the practice they need. However, unstructured written work does not ensure development. I would argue that teachers of advanced ESP courses who wish to include report writing in their syllabi should first rather prepare their students to meet three challenges:

1) Even upper-intermediate students often lack a proper understanding of what is meant by report writing.

2) Almost all university students require either a thorough introduction to how to professionally layout a report acceptable in both the academic and business worlds.

3) Students will inevitably need practical modules in presenting their finished reports.

To better prepare classes to return on due dates with completed assignments which meet teacher expectations, we as university ESP instructors must stop assuming that our first year students grasp how to properly write in their native language. My criticism is based on six years' experience in Hungarian ESP teaching, discussions with colleagues and countless hours of proofreading hopelessly 'malcomposed' essays, in courses including General Conversation, Culture and Civilization, Academic Writing, and Introduction to Professional Written Communication.

For whatever reason, our students entering university are not being properly prepared to face the academic challenges that await them with universitylevel written assignments. Advanced ESP courses provide only one possibility of remedying this educational gap, as our departments can uniquely assign students written work within a wide range of academic subject material as its basis.

Report writing is an excellent example of how we can achieve the necessary goal of training our graduates to communicate in a professional world dominantly dependent on information exchange. ${ }^{1}$
We need to inform our students that reports are not pointless writing exercises meant to give them something to do until next week's class, and rather that these assignments represent a tool for widening their knowledge in another subject area they find vital for their future careers. Creating reports involves several key areas, each taken singularly in themselves a vital skill:

* Problem-solving

* Role-playing (e.g., writing a report for a client)

* Researching

* Opinion formation based on one's research

* Logic and organization

* Exercising objectivity and subjectivity

* Use of tables, graphs and software

* Using proper citations forms (quotes, footnotes, endnotes, and bibliographies)

* Use of paraphrasing and summaries

* Precision

How do we assist our students to develop all these skills? First, we should ourselves understand what the professional world terms report writing to be.

A good report requires careful attention to the process of composition, and I would especially emphasize the term process here. Students need to be made to understand that writing is indeed a step-bystep procedure, and not an assignment they can possibly write well the night before a paper is due.

Many writing programs in American English departments rely on a seven step approach which is not only easy for teachers to learn, but also easy to teach. Step One is to identify the purpose of the report. This simple prerequisite is the key to the success of the entire process. Experience has proven that unless students are sure about the purpose of their assignments, they will probably fail to use relevant arguments, or even come to well-grounded conclusions. Therefore, always ensure that each student clearly identifies the purpose of the report or, if a report assignment is to cover the same topic for all the class participants, that you clearly state its purpose in front of your class, before allowing it to proceed. Often, purpose identification will take the form of a single sentence about the problem, issue or question to be interrogated. Purposes may be, for example, to assist in decision-making, problem solving, persuading others to change their opinions, to adopt new ideas, or even to reject them. Regardless of whichever purpose chosen or assigned, even developing such a statement should require reflection and analysis. Have the students do some

\footnotetext{
${ }^{1}$ See David A. McMurrey, Introduction to Technical Communication Course Guide. (University Co-op: Austin, 1998), and Troy B. Wiwczaroski, An Introduction to Writing for Professional Communication. (DE ATC: Debrecen, 2000), 21ff.
} 
initial reading before pinning down a single objective.

Step Two is to identify the readers, i.e. the audience, and its needs. Ensure that the students understand that they must tailor their writing to a target group, selectively using background sources, quotes and arguments, each geared toward meeting a clear objective: the purpose they identified in Step One. Have your students imagine that you are not their audience, but rather that they are explaining something to an individual who is either 1) intelligent enough to be one of your colleagues, 2) who possesses a reasonable amount of common sense, or 3) knows almost nothing about their chosen subject. Ask them to identify those elements they wish to discuss which are (ir)relevant to use for one of these three possible audiences, and to include or edit out accordingly.

Step Three involves researching the topic more thoroughly. We should demand that our students use not only the most relevant, but equally importantly, the most current research in their work. Encourage them to turn to the Internet, but ensure thorough use of library holdings, as well. You may need to arrange for the university librarians to give the students an 'expert tour'. Never assume the students know where to look for source literature, much less how to do so, or even that they know what holdings the library offers. Numerous times early in my own career, I returned on assignment day to face a class claiming it had "not been able to find anything in the library or on the Internet on the topic". Such problems point not to laziness on the part of the class, but to their lack of knowledge about how to conduct research. Therefore, a 'class trip' to the library involving a thorough introduction to the world of secondary literature is never a wasted class day. After all, only those who possess first-hand knowledge of where to find information on a given subject will be able to find valuable sources and then put them to good use. You must make sure that the tour includes information on where to find not only periodicals by subject or discipline, but also holdings of theses, conference proceedings, annual reports, special archives and collections, microfilmed materials and especially the latest publications of the university's own faculty. Once introduced to all these treasures, build into your report writing guidelines that the student include in their bibliographies sources from several of the given research categories. Only if we dictate that students use sources from a wide variety of secondary materials will they ever do so.

Next, we should emphasize the value of collecting such a variety of materials, so our students will understand why we are pushing them to work in a way unfamiliar to many of them. The goal of this discussion should be to arm the class with the proper insight on 1) the nature of the problem, 2) the correct use of terminology, and 3) the understanding of theoretical data and argumentation. We should also tell the students that this method of research should acquaint them with theories and methods they have as yet not even considered, but which we, their instructors, have. Have the students always ask themselves what is really relevant and what is merely repetitious.

Another assumption teachers often mistakenly have about their students is that they have learned good research methods. They most oftentimes have not. The easiest way to teach them how to use research materials is to insist that they use note cards, either alphabetically arranged by subject or author. There are two kinds of note cards: The first they should use to cite author, date of publication, title, publisher, place of publication and page numbers. The other is the card onto which they write down the actual notes. Stress the necessity to your class that they use the actual note cards to make three types of notes: 1) for jotting down important quotations, 2) for making summaries of important background information, and 3) for writing their own paraphrases of the original sources. This way, they will be less likely to plagiarize or overly use quotes in their writing. Another way to tackle the plagiarism problem is to ask the class to show you their note cards periodically, onto which they must write in the upper-right hand corner of each card the symbols Q (quote), $\mathrm{P}$ (paraphrase) or $\mathrm{S}$ (summary). This will help them to keep track of how they are using which sources, and also make the actual task of properly documenting their sources in their final drafts easier.

Once the students have completed their research, they should move on to Step Four, or to making an outline. To do so, they should first review, synthesize and interrogate their gathered information. Have them focus on the body of their reports, leaving the introduction and conclusion for last. They will find it easier to start in this way, as many writers find it daunting to try to actually begin the writing process. This is especially true for younger, less experienced writers, such as students who have yet to explore topics on paper. In preparing their outlines, the students should experiment with 3-5 major headings that will define their overall thinking on the subject. Within each of these major sections, they will present facts, debunk misunderstanding and untruths, give explanations, reasoning and conclusions. At the end of their argumentation, they should make some recommendation(s). Have the students look for commonalities, while doing so under the rubric of their already established report purposes. In the outline itself, each section heading must clearly and briefly indicate its content. Next, the student should regroup them, checking for logical sequence. Always ensure that your students revise their outlines for what best suits their stated purpose.

Step Five is to write the draft. Here, it is vital that the student pays more attention to their ideas, evidence, supporting documentation and logical flow, than punctuation or typing errors. Encourage them to actually put pen to paper. Drafts done on the computer alone often have the downside that grave logical errors as committed, as the student cannot see the entire page at one time. Also, self-editing is a hard enough task for any writer. Without a hard copy, the great majority of students simply will not be able 
to proofread on any acceptable level, much less in a foreign language.

Students should be made to understand that they are to form their own lines of argument based on their research findings, and not simply from ideas they developed on their own. Reports are based on established, supported facts, and not hypotheses. They should express their own ideas in their own words, while demonstrating how their ideas were formed, influenced or changed by the writings of their source authors. Then, they should show how their own argument has incorporated the ideas it has from the research material, and why. The use of quotations is certainly not forbidden, but the over-use of quoting should be strongly discouraged, in favor of paraphrasing or summary writing.

A vital, yet oftentimes overlooked, element of draft writing is that of impartiality. Students should be encouraged to express themselves objectively. Consequently, report writing is most commonly done in the third person, and past tense. For example, instead of writing "We conducted this study...", write "The purpose of this study was to...”. Remind students also to write clearly and concisely, avoiding contradictory statements, and always without the use of contractions or slang.

Step Six is to edit the draft for clear expression of ideas, sense, logic and consistency. I highly recommend that you press your students to proofread each other. They can learn a great deal from each other in this way, and the effect of peer pressure on performance is quite remarkably positive. Proofreading should involve not just checking for poor grammar and spelling, but also the elements of inconsistent argumentation, typographical errors and logical organization of ideas.

The final, seventh step is to put together the finished form of the paper. This includes choosing a professional layout for visual appeal, using for example an applicable typing font. However, the final step also means additional proofreading for consistency in typing and page layout. Students should be consistent in when and why they used bolded or italicized type, when, why and how they used bullet points, page numbers, citation forms and subheadings. In brief, the structure should be unified.

The above has been a brief introduction to report writing. Managing the process with students requires ample investment of our time, but this investment is richly rewarded in the form of the handed-in final assignments, not to mention the development of student performance. By clarifying to our students the professional necessity to write well, by teaching them the steps of the report writing process, by reinforcing writing skills within and without of this process, and by providing our classes the opportunity to explore complex subject matter in depth, we will successfully prepare our students for their professional tomorrows. We will also find our own teaching more rewarding, because the fruits of our labors will be more visible.

\section{REFERENCES}

Elbow, P. (1998): Writing with Power: Techniques for Mastering the Writing Process. Oxford University Press, Oxford

Graham, L. (1995): How to Write a Great Research Paper: A Stepby-Step Guide. Barrons, New York

Launius, C. J.-Self, D. J. (1999): Wordwright Guide to College Writing. Phoenix International, Phoenix

McMurrey, D. A. (1998): Introduction to Technical Communication Course Guide. University Co-op Press, Austin
Royster, J. J. (2000): Writing and the Public Good: A Casebook for Thinking and Writing. Addison, New York

Wiwczaroski, T. B. (2000): An Introduction to Writing for Professional Communication. DE ATC, Debrecen

Everyone Can Write: Essays Toward a Hopeful Theory of Writing and Teaching Writing. Oxford University Press, Oxford, 2000 